\title{
Cross-border ties, nativity, and inflammatory markers in a population-based prospective study of Latino adults
}

\author{
Jacqueline M. Torres $^{\mathrm{a}, *}$, Elissa S. Epel ${ }^{\mathrm{b}}$, Tu My To ${ }^{\mathrm{a}}$, Anne Lee ${ }^{\mathrm{a}}$, Allison E. Aiello ${ }^{\mathrm{c}}$, Mary N. Haan \\ a Department of Epidemiology and Biostatistics, University of California, San Francisco, 550 16th Street, San Francisco, CA, 94143, United States \\ ${ }^{\mathbf{b}}$ Center for Health \& Community, University of California, San Francisco, United States \\ ${ }^{c}$ Gillings School of Public Health, University of North Carolina, Chapel Hill, United States
}

\section{A R T I C L E I N F O}

\section{Keywords:}

Transnationalism

Inflammation

Social ties

Nativity

Latinos

\begin{abstract}
A B S T R A C T
Even after migration, immigrants and their descendants may continue to have ties to family and friends who remain in places of origin. Recent research suggests that these cross-border social ties have implications for health, although this scholarship has been limited to self-reported outcomes. Using data from the Sacramento Area Latino Study on Aging (SALSA), we estimate associations between cross-border social ties and inflammatory biomarkers among Latino adults $(n=1786)$. We find that immigrants who maintained any crossborder connection to family and friends in Latin America had significantly lower levels of baseline interleukin- 6 (IL-6) and C-reactive protein (CRP) compared to their US-born counterparts with no cross-border ties. These results held for values of CRP at five-year follow-up for men only. In contrast, US-born women with cross-border ties to family and friends in Latin America had both significantly higher levels of CRP and significantly lower levels of tumor necrosis factor-alpha (TNF- $\alpha$ ) at five-year follow-up relative to their US-born counterparts with no cross-border ties. We find descriptively that men who have cross-border ties are also less likely to be socially isolated within local contexts. Considering place-of-origin social connections may contribute critical nuance to studies of immigrant health, including disparities in inflammatory markers that may serve as indicators of underlying chronic disease.
\end{abstract}

Building on a long-standing body of research linking social relationships to health (Berkman et al., 2000), recent work has investigated links between social relationships and inflammatory markers (Bajaj et al., 2016; Glei et al., 2012; Yang et al., 2016; Yang et al., 2014) that may serve as early indicators of subsequent morbidity (Das, 2016; Ridker et al., 2000a; Ridkeret al., 2000b) and mortality (Kaptoge et al., 2010). These studies have found some evidence that social relationships influence inflammatory markers, including pro-inflammatory cytokines such as interleukin-6 (IL-6) and acute phase proteins (e.g. C-reactive protein) (Ford et al., 2006; Loucks et al., 2006; Yang et al., 2016), although findings overall have been mixed, with some evidence of null or modest associations (Bajaj et al., 2016; Glei et al., 2012).

Notably, the extant research has been largely limited to US-born non-Latino white respondents, and has therefore given less consideration to the sociocultural context of family and community networks for US immigrants and their descendants. This paper extends recent research on the links between social relationships and inflammatory biomarkers to a population-based sample of older Latino adults 60 years and older. Pro-inflammatory cytokines IL- 6 and tumor necrosis factor- alpha (TNF- $\alpha$ ) have been linked to all-cause and cardiovascular disease mortality (Roberts et al., 2010) and C-reactive protein has been linked to functional impairment (Aiello et al., 2008) and cognitive decline (Yaffe et al., 2007) in this sample, underscoring the wide-ranging implications for multiple health outcomes.

We carry out this work with a transnational framework, which acknowledges the potential for immigrants to maintain social connections to family and friends both locally and in places of origin (AcevedoGarcia et al., 2012). We therefore estimate associations between both cross-border and local social connection and inflammation in our sample. This work builds from recent research that suggests that continued cross-border ties are significantly associated with mental health and health behaviors for both immigrants and their US-born descendants, even after accounting for local social connections to family and community members (Alcántara et al., 2015a; Alcántara et al., 2015b; Torres et al., 2016a, b). Finally, we examine whether cross-border ties might reveal potential heterogeneity in the relationship between nativity and inflammation. While immigrants have been found to have lower levels of inflammation than their US-born counterparts

\footnotetext{
Abbreviations: (CRP), C-Reactive Protein; (IL-6), Interleukin-6; (SALSA), Sacramento Area Latino Study on Aging; (TNF- $\alpha$ ), Tumor Necrosis Factor- $\alpha$; (US), United States

* Corresponding author.

E-mail address: Jacqueline.Torres@ucsf.edu (J.M. Torres).
} 
(Crimmins et al., 2007; Peek et al., 2010), it is possible that this immigrant "advantage" in inflammation differs by whether or not immigrants are connected to places of origin.

\section{A transnational approach to the study of social relationships and inflammation}

Inflammation is a potential biological mediator linking social relationships to multiple health outcomes (Eisenberger and Cole, 2012; Kiecolt-Glaser et al., 2010). Social connections may influence inflammation by activating responses in neural and endocrine systems (Eisenberger and Cole, 2012). Social relationships may also influence health behaviors, such as smoking and physical activity, that in turn contribute to systemic inflammation (Kiecolt-Glaser et al., 2010). While the relationships between social relationships and inflammation have been tested in population-based data sources (Glei et al., 2012; Yang et al., 2014, 2016), this work has incorporated limited nuance regarding the sociocultural particularities of family and community networks for diverse populations, including immigrants and their US-born children.

Scholars have recently emphasized the importance of incorporating a transnational perspective into research on the social determinants of health for immigrants and their family members (Abraído-Lanza et al., 2016). A transnational perspective emphasizes the connections that immigrants and their descendants often maintain with family and friends in places of origin even as they develop social relationships within communities in the US (Waldinger, 2015). These place-of-origin connections may be in the form of return visits, the transmission of remittances, or communication by phone or the Internet. A nascent body of immigrant health scholarship has considered the potential influence of these cross-border social relationships on self-reported health and health behaviors (Alcántara et al., 2015a; Alcántara et al., 2015b; Torres et al., 2016a, b; Villa-Torres et al., 2017), although this work has yet to examine whether these associations with self-reported measures extend to biological indicators of health, including inflammatory markers.

Scholars have, however, proposed a number of potential psychosocial and behavioral mechanisms that may explain any observed association between cross-border ties and inflammation (Torres et al., 2016a; Villa-Torres et al., 2017; Viruell-Fuentes and Schulz, 2009), which we review below. Each of these mechanisms may have countervailing protective and adverse implications for inflammation (see conceptual framework in Supplemental Appendix). Although we are secondarily interested in the role of local social relationships, the potential mechanisms linking local social relationships within family and community networks and inflammation have been addressed elsewhere (Kiecolt-Glaser et al., 2010). However, we note that cross-border connection may also intersect in important ways with social relationships as well as social isolation - experienced in the US. It may be that those who have fewer social connections in the US are more likely to engage with family and friends across borders as a way of coping. On the other hand, those who have strong social networks in the US could rely less on cross-border ties for emotional, instrumental, or informational support (Waldinger, 2015).

\section{Cross-border social ties and inflammation: possible psychosocial pathways}

Connection with family and friends in places of origin may have protective effects on inflammation through both supportive and stressexacerbating psychosocial pathways. For one, family and friends abroad may serve as a critical source of support and a provide a sense of belonging within a cross-border family network and/or ethnonational community (Viruell-Fuentes and Schulz, 2009). Scholars have documented through qualitative research that family and friends who remain in places of origin often continue to provide social, informational, and instrumental support to immigrants and their family members lending an ear to discuss challenging emotional experiences related to living in the US, or providing advice about medical care or home remedies, for example (Menjívar, 2002; Villa-Torres et al., 2017). This support and sense of belonging is often critical as immigrants and their family members experience social isolation and marginalization in the US. Continued cross-border social connection may in turn contribute to lower levels of inflammation through pathways of reduced depression and elevated social and instrumental supports (Kiecolt-Glaser et al., 2010).

There may also be potentially adverse implications of cross-border ties for inflammation among immigrants and their family members, which may occur through stress-related pathways. Immigrants may continue to provide emotional or financial support to family members across borders, possibly in addition to caring for family members locally (Abrego, 2014; Viruell-Fuentes, 2006). Qualitative scholarship has uncovered the particularly acute burden of cross-border caregiving for immigrant women, who may be charged with coordinating and providing care to family members both at home and abroad (ViruellFuentes, 2006). Chronic stress resulting from family strain and caregiving burden in general has been linked to higher levels of inflammation (Kiecolt-Glaser et al., 2003). While the potential for social strain and the burden of caregiving is not unique to cross-border relationships, cross-border ties are unique from local ties in that they occur in a context of cross-border separation (Menjívar, 2012). That is, family members connect across borders because they are separated across borders. Often this separation is the result of immigration policies that make it difficult for immigrants to return to places of origin, or that make family reunification in the US a legal or financial impossibility (Abrego, 2014; Menjívar, 2002). Prior research finding significant, adverse associations between cross-border ties and the psychological wellbeing of immigrant women in population-based studies of US Latinos may reflect the strain of cross-border separation and caregiving that often accompanies these transnational connections (Alcántara et al., 2015a; Torres et al., 2016b).

\section{Cross-border social ties and inflammation: possible behavioral pathways}

Cross-border ties may also be linked to inflammatory markers through behavioral pathways. As the result of primarily qualitative research, scholars have suggested that cross-border ties may facilitate immigrants' ongoing exposure to behavioral norms and preferences of communities of origin (Villa-Torres et al., 2017). These norms and preferences may include health behaviors that may be reflected in inflammatory markers. In one of the few empirical tests of the potential associations between cross-border ties and health behaviors, Alcántara et al. (2015b) found significant cross-sectional associations between cross-border ties -measured as the number of return visits to place of origin per year, and remittance-sending to family and friends in Latin America- and lower odds of being a current smoker in a national sample of Latino migrants. The protective association between remittance-sending and smoking status was particularly pronounced for Latina women.

Cross-border ties may also have implications for other health-related behaviors, including interaction with the health care system, selfcare practices, and medication adherence (Villa-Torres et al., 2017). Specifically, immigrants and their descendants who maintain crossborder ties may be more likely to return to places of origin for health care; seeking health care in places of origin may be preferred for those who experience barriers to care in the US, or who are accustomed to systems of care in places of origin. Even for those who are not able to travel due to legal, financial, or health-related constraints, cross-border social ties may serve as channels of health-related information, including traditional self-care practices (Villa-Torres et al., 2017). 


\section{Cross-border social connection and the immigrant} inflammation advantage

In addition to the potential main effect association between crossborder ties and health, including biological indicators of health, connection to place of origin may serve as a source of heterogeneity in the relationship between nativity and health. Researchers have long documented significant health advantages for immigrants relative to their US-born counterparts (Daviglus et al., 2012; Medina-Inojosa et al., 2014). The so-called immigrant health "advantage" has been tentatively explained by a number of factors, including the selectivity of individuals into the migration process based on positive health characteristics (Jasso et al., 2004) and the return migration of less healthy immigrants to places of origin (Arenas et al., 2015). There is some evidence that the immigrant advantage extends to inflammation (Crimmins et al., 2007; Peek et al., 2010), although extant studies have yet to consider sociocultural sources of heterogeneity in the relationship between nativity and inflammation among immigrants and their US-born descendants.

We seek to understand whether or not both cross-border ties to one's country of origin - or parents' country of origin - may be one such source of heterogeneity, given the potential for continued cross-border connection to impact other dimensions of health (e.g. mental health, health behaviors), which may in turn influence levels of inflammation. For example, cross-border connection might buffer the potentially adverse effects of social isolation US by offering positive psychological resources (e.g. support, a sense of belonging) for immigrants and their US-born children (Viruell-Fuentes and Schulz, 2009) and serving as a path for ongoing exposure to behavioral norms places of origin which may be more health-promoting than those in the US (Villa-Torres et al., 2017). Similarly, US-born descendants of Latin American-origin immigrants who maintain social connection to Latin America may enjoy health advantages relative to their US-born counterparts without these cross-border ties; these US-born Latinos could share social, cultural, and behavioral profiles that are more similar to their immigrant counterparts.

\section{The present study}

While the potential influence of cross-border social relationships on health outcomes has been suggested in both qualitative research and quantitative analyses of self-reported health outcomes, there has yet to be a link to biological indicators of health. We therefore estimate the associations between an indicator of cross-border social ties and three inflammatory markers in a population-based sample of older Latino adults. We expect to find positive associations between cross-border connection and inflammatory markers, although we acknowledge the potential for null or even negative results given the fact that crossborder relationships may also entail stress and burden, particularly for immigrant women. We secondarily examine the relationship between local social integration and inflammation, expecting that more local social relationships will also be significantly associated with lower inflammation in the sample.

Finally, we examine the relationship between cross-border ties and inflammation by respondent nativity. Specifically, we expect that immigrant respondents will have lower levels of inflammation relative to their US-born counterparts, but that this advantage will be even greater for those who have cross-border connection through social ties to family and friends in Latin America. Conversely, we expect that while USborn respondents overall will have higher levels of inflammation relative to their immigrant counterparts, US-born respondents with no connection to Latin America (i.e. parents' place of origin) will have the highest levels of inflammation across all groups, given that this group would likely not benefit from the potentially health-protective components of cross-border connection.

\section{Methods}

\subsection{Data}

The Sacramento Area Latino Study on Aging (SALSA) is a population-based, prospective study of foreign and US-born Latino respondents living in the Sacramento Valley region of Northern California. Respondents were 60-101 years old at baseline and 94\% were of Mexican origin; $6 \%$ of the sample was born in Central America. All census tracts in the six contiguous counties of the Sacramento Valley with at least $5 \%$ eligible (i.e. Latino and $\geq 60$ years) based on 1990 Census data were considered. All households within these tracts were enumerated and all residents with Latino surnames $\geq 60$ years were contacted by mail, phone, or door-to-door. All eligible members of a household were included in the survey. Among those contacted, 85\% ( $n=1789$ ) completed the initial survey. As described in greater detail elsewhere (Haan et al., 2003), the baseline sample shared similar demographic characteristics to older Latinos in the region as described by the 1998 dress rehearsal for the 2000 US Census. After the baseline visit, home visits were completed every 12-15 months through 2008. Semi-annual phone calls were made to update contacts and health status.

\subsection{Outcome measures}

A fasting blood sample was drawn on the day of the interview at baseline and follow-up waves; inflammatory markers are available at baseline and the fourth follow-up wave, which was conducted approximately five-years after baseline (2004/2005). Frozen (-70C) serum samples were analyzed for tumor necrosis factor-alpha (TNF- $\alpha$ ), Interleukin-6 (IL-6), and high-sensitivity C-reactive protein (CRP) at baseline and the fourth follow-up wave. High sensitivity C-reactive protein levels were tested using the CRP Ultra Wide Range Reagent Kit latex-enhanced turbidimetric immunoassay (Ledue et al., 1998) (Genzyme Diagnostics (formerly Equal Diagnostics), Exton, Pennsylvania). TNF- $\alpha$ and IL- 6 levels were determined by using the Quantiglo Chemiluminescent Immunoassay (R\&D Systems Inc., 2017a, 2017b).

\section{Exposure measures}

\subsection{Cross-border social connection}

At baseline, respondents were asked about how frequently they spoke to family or friends in Latin America. We contrasted those who reported talking "often", "always", or "almost never" to those who reported "never" talking to family or friends abroad (Viruell-Fuentes, 2006). We additionally examined a four-category measure of crossborder ties and nativity (i.e. U.S.-born or born in Latin America). We examined the sensitivity of findings to a different specification of the cross-border ties measure (i.e. contrasting those who reported "often" or "always" with those who reported talking "almost never" or "never") (see Supplemental Appendix). We prefer the specification of crossborder ties employed in the primary analyses (i.e. indicative of any cross-border contact versus none at all), given prior research suggesting that even very little communication with family and friends abroad can have substantial emotional and symbolic value for immigrants and their family members (Torres, 2013; Viruell-Fuentes, 2006).

\subsection{Local social relationships}

Local social relationships at baseline were captured with measures related to family members in the household as well as markers of social activities outside the household that might proxy for community or workplace social connections. Respondents were assigned a one (1) for each of the following indicators: living with a spouse; living with children or other non-spouse family member or friends; currently 
working outside the home; and engaging in volunteer activities. These indicators were summed, yielding a count of local social relationships (range 0-3).

\subsection{Potential confounders}

We selected a parsimonious list of potential confounders, including age in years, economic status, and depression. Economic resources likely influence the capacity of individuals have to maintain crossborder connections through return visits and/or remittance-sending to family and friends abroad - and may also influence inflammation. Economic status was measured with an indicator of gross monthly household income divided by the number of individuals living in the household. Household income was available as a five-category measure (i.e. less than $\$ 1000 /$ month, $\$ 1000$ to $\$ 1499 /$ month, $\$ 1500$ to $\$ 1999$ / month, $\$ 2000$ to $\$ 2499 /$ month, $\$ 2500$ or more/month), and was recoded to reflect the mid-point of each category (i.e. $\$ 500, \$ 1249.5$, $\$ 1749.5$, \$2249.5, \$2479.5) before dividing by number of household members (range: 0 to 12 ).

While depression may serve as a mediator of the relationship between social relationships and inflammation (see Fig. 1), it is also a potential confounder, given that depression may impact individuals' social engagement with family and community members, as well as inflammation. We therefore controlled for depression with the 20-item Centers for Epidemiologic Studies Depression (CES-D) scale (Radloff, 1977); those with CES-D scores of 16 or greater were compared with those scoring below 16 .

For completeness, we also present models in the Supplemental Appendix that control for potential mediators, including body mass index, smoking status, physical activity, and anti-inflammatory medication usage. We do not consider these final models of primary interest given that the inclusion of mediators of our main association of interest likely amounts to over-control.

\subsection{Statistical analyses}

We first examined descriptive characteristics stratified by gender, given prior research suggesting that relationships between both crossborder social connections and health differ substantially for men and women (Alcántara et al., 2015b; Torres et al., 2016b). We subsequently examined bivariate associations between local and cross-border social relationships in order to examine patterns of transnational social relationships in the sample.

We then estimated age-adjusted associations between the baseline cross-border social relationship measures and individual inflammatory markers using Ordinary Least Squares regression models (Model 1). Inflammatory markers were log-transformed due to highly skewed distributions; we present exponentiated regression coefficients, which can be interpreted as estimates of the percent change in the outcome corresponding to a one-unit change in the predictor variable of interest. We subsequently included measures of local social relationships, nativity, economic status, and depression (Model 2). We then re-estimated models using a four-category measure of cross-border ties and nativity. Finally, we estimated the associations between baseline cross-border connection, nativity, and inflammatory markers measured at the fourth follow-up wave (i.e. five years after baseline).

We addressed missing data on baseline measures with multiple imputation. A total of 30 datasets were generated using iterative chained equations with the -ice-package in STATA v. 14. Three cases were missing across multiple indicators and could not be imputed, leading to a baseline analytic sample of 1786. For analyses of inflammatory markers at five-year follow-up, we utilized the imputed datasets from the baseline models for exposure and covariate measures, but restricted our analyses to respondents who had non-missing values on five-year follow-up measures of inflammation ( $\mathrm{n}=935$ for CRP, $\mathrm{n}=594$ for IL- 6 and TNF- $\alpha$ ). Compared to those who left the survey
Table 1

Descriptive statistics for a population-based study of Latino adults 60 years and older by respondent gender $(\mathrm{n}=1786)$.

Source: Sacramento Area Latino Study on Aging (SALSA).

\begin{tabular}{|c|c|c|c|c|}
\hline & \multicolumn{2}{|c|}{ Women $(n=1043)$} & \multicolumn{2}{|c|}{ Men $(n=743)$} \\
\hline \multicolumn{5}{|l|}{ Baseline Covariates } \\
\hline $\begin{array}{l}\text { Talk to family and friends in Latin } \\
\text { America, } \mathrm{n}(\%)\end{array}$ & 471 & $(45.2)$ & 343 & $(46.2)$ \\
\hline Latin American-born, n (\%) & 549 & $(52.6)$ & 362 & $(48.7)$ \\
\hline \multicolumn{5}{|l|}{ Potential Confounders } \\
\hline Age, mean (sd) & \multicolumn{2}{|c|}{$70.8(7.3)$} & \multicolumn{2}{|c|}{$70.5(6.9)$} \\
\hline $\begin{array}{l}\text { Monthly household income } \geq \$ 1500 \text {, } n \\
\text { (\%) }\end{array}$ & 269 & $(25.8)$ & 350 & $(47.1)$ \\
\hline $\begin{array}{l}\text { Local social connections, range (0-3), } \\
\text { mean (sd) }\end{array}$ & \multicolumn{2}{|c|}{$1.3(0.8)$} & \multicolumn{2}{|c|}{$1.6(0.8)$} \\
\hline Depression (CES-D $\geq 16$ ), n (\%) & 339 & $(32.5)$ & 125 & $(16.8)$ \\
\hline \multicolumn{5}{|l|}{ Potential Mediators } \\
\hline $\begin{array}{l}\text { Any anti-inflammatory medication, } \mathrm{n} \\
\quad(\%)\end{array}$ & 601 & $(57.6)$ & 392 & $(52.8)$ \\
\hline Body mass index, mean (sd) & \multicolumn{2}{|c|}{$29.9(6.5)$} & \multicolumn{2}{|c|}{$29.2(5.0)$} \\
\hline Ever smoked, n (\%) & 398 & $(38.2)$ & \multirow{2}{*}{\multicolumn{2}{|c|}{$\begin{array}{l}566 \\
84.8(83.9)\end{array}$}} \\
\hline Physical activity ${ }^{\mathrm{a}}$, mean (sd) & \multicolumn{2}{|c|}{$59.9(66.5)$} & & \\
\hline \multicolumn{5}{|l|}{ Baseline Inflammatory Markers } \\
\hline Mean IL-6, mg/dL, mean (sd) & \multicolumn{2}{|c|}{$5.47(7.7)$} & \multicolumn{2}{|c|}{$4.83(4.8)$} \\
\hline Mean TNF- $\alpha$, mg/dL, mean (sd) & \multicolumn{2}{|c|}{$4.27(2.7)$} & \multicolumn{2}{|c|}{$4.22(3.0)$} \\
\hline Mean CRP, mg/dL, mean (sd) & \multicolumn{2}{|c|}{$7.02(14.5)$} & \multicolumn{2}{|c|}{$4.60(8.3)$} \\
\hline $\begin{array}{l}\text { Inflammatory Markers, 5-Year } \\
\quad \text { Follow-Up }\end{array}$ & \multicolumn{2}{|c|}{ Women $(n=350)$} & \multicolumn{2}{|c|}{ Men $(n=248)$} \\
\hline Mean IL-6, mg/dL, mean (sd) & \multicolumn{2}{|c|}{$4.42(12.6)$} & \multicolumn{2}{|c|}{$3.29(4.8)$} \\
\hline Mean TNF- $\alpha$, mg/dL, mean (sd) & \multicolumn{2}{|c|}{$4.26(16.3)$} & \multicolumn{2}{|c|}{$3.25(1.9)$} \\
\hline & \multicolumn{2}{|c|}{ Women $(n=550)$} & \multicolumn{2}{|c|}{ Men $(n=389)$} \\
\hline Mean CRP, mg/dL, mean (sd) & \multicolumn{2}{|c|}{$5.56(8.2)$} & \multicolumn{2}{|c|}{$4.48(10.4)$} \\
\hline
\end{tabular}

a Physical activity was measured as metabolic equivalents of task hours per week spent doing moderate to vigorous physical activities, including walking, dancing, hunting or camping or boating, swimming or engaging in workouts, golfing or other moderate exercise, gardening or yardwork, house repairs, and heavy housework.

due to death or loss-to-follow-up, those who remained in the follow-up sample were younger, less likely to be Latin American-born and, particularly for men, less likely to have had any cross-border connection at baseline. Models of inflammation at five-year follow-up incorporate stabilized inverse probability of attrition weights (IPAWs). The weights were truncated at the 99th percentile (Cole and Hernán, 2008). Estimates were replicated both with and without exclusion of cases with values \pm 4 SD around the mean of each inflammatory marker; we report on differences in models that excluded outliers in a Supplemental Appendix.

\section{Results}

Table 1 shows that just under half of respondents (45\% of women, $46 \%$ of men) reported any communication with family and friends in Latin America at baseline. Respondents had an average score of about 1.5 (SD: 0.8) on the count measure of local social relationships (range $0-3)$. There were no significant bivariate associations between crossborder and local social relationships measures for women. However, men who reported cross-border connection were also more likely to have more local social connections ( $\mathrm{p}<0.001$ ). Twenty-one percent of men with any baseline cross-border connection had three or more local social relationships compared to $12 \%$ of those who reported no crossborder connection. In contrast, $6 \%$ of men who reported any baseline cross-border connection had zero local social relationships compared to $12 \%$ of those with no cross-border connection.

In age-adjusted regression models, there were significant associations between having any cross-border connection and lower levels of baseline IL-6 $(\operatorname{Exp}(\beta)=0.90,95 \%$ CI: $0.81,0.99$ for men, $\operatorname{Exp}$ $(\beta)=0.88$, 95\% CI: $0.81,0.96$ for women), lower baseline CRP for 
Table 2

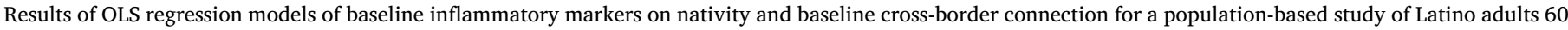
years and older, Sacramento Area Latino Study on Aging.

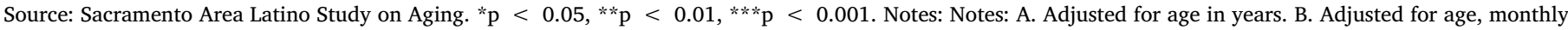
income divided by the number of individuals living in the household, depression, and local social integration, all measured at baseline.

\begin{tabular}{|c|c|c|c|c|c|c|c|c|c|c|c|c|}
\hline & \multicolumn{6}{|c|}{ Women $(n=1043)$} & \multicolumn{6}{|c|}{ Men $(n=743)$} \\
\hline & \multicolumn{3}{|l|}{ Model $1^{\mathrm{a}}$} & \multicolumn{3}{|l|}{ Model $2^{\mathrm{b}}$} & \multicolumn{3}{|c|}{ Model $1^{\mathrm{a}}$} & \multicolumn{3}{|l|}{ Model $2^{\mathrm{b}}$} \\
\hline & & & & & & & Log IL-6 & & & & & \\
\hline Nativity/Cross-Border Connection & $\operatorname{Exp}(\beta)$ & $95 \% \mathrm{CI}$ & & $\operatorname{Exp}(\beta)$ & $95 \% \mathrm{CI}$ & & $\operatorname{Exp}(\beta)$ & $95 \% \mathrm{CI}$ & & $\operatorname{Exp}(\beta)$ & $95 \% \mathrm{CI}$ & \\
\hline U.S.-born, No Cross-Border Connection & Ref & Ref & Ref & Ref & Ref & Ref & Ref & Ref & Ref & & Ref & Ref \\
\hline U.S.-born, Any Cross-Border Connection & 0.95 & $(0.80,1.13)$ & & 0.96 & $(0.81,1.13)$ & & 1.02 & $(0.87,1.19)$ & 1.02 & $(0.87,1.20)$ & & \\
\hline Latin American-born, No Cross-Border Connection & 0.97 & $(0.85,1.11)$ & & 0.93 & $(0.81,1.07)$ & & 0.89 & $(0.75,1.05)$ & 0.85 & $(0.71,1.00)$ & & \\
\hline \multirow[t]{3}{*}{ Latin American-born, Any Cross-Border Connection } & 0.85 & $(0.77,0.94)$ & $* *$ & 0.81 & $(0.73,0.90)$ & $* * *$ & 0.82 & $(0.73,0.92)$ & $* *$ & 0.78 & $(0.69,0.88)$ & $* * *$ \\
\hline & \multicolumn{12}{|c|}{ Log CRP } \\
\hline & $\operatorname{Exp}(\beta)$ & $95 \% \mathrm{CI}$ & & $\operatorname{Exp}(\beta)$ & $95 \% \mathrm{CI}$ & & $\operatorname{Exp}(\beta)$ & $95 \% \mathrm{CI}$ & & $\operatorname{Exp}(\beta)$ & $95 \% \mathrm{CI}$ & \\
\hline U.S.-born, No Cross-Border Connection & Ref & Ref & Ref & Ref & Ref & Ref & Ref & Ref & Ref & Ref & Ref & Ref \\
\hline U.S.-born, Any Cross-Border Connection & 0.90 & $(0.68,1.20)$ & & 0.91 & $(0.68,1.21)$ & & 1.10 & $(0.82,1.47)$ & 1.09 & $(0.81,1.46)$ & & \\
\hline Latin American-born, No Cross-Border Connection & 0.89 & $(0.71,1.11)$ & & 0.85 & $(0.68,1.06)$ & & 0.93 & $(0.70,1.24)$ & 0.88 & $(0.67,1.17)$ & & \\
\hline \multirow[t]{3}{*}{ Latin American-born, Any Cross-Border Connection } & 0.78 & $(0.66,0.93)$ & $* *$ & 0.74 & $(0.62,0.89)$ & $* *$ & 0.81 & $(0.65,1.00)$ & 0.74 & $(0.57,0.93)$ & * & \\
\hline & \multicolumn{12}{|c|}{ Log TNF- $\alpha$} \\
\hline & $\operatorname{Exp}(\beta)$ & $95 \% \mathrm{CI}$ & & $\operatorname{Exp}(\beta)$ & $95 \% \mathrm{CI}$ & & $\operatorname{Exp}(\beta)$ & $95 \% \mathrm{CI}$ & & $\operatorname{Exp}(\beta)$ & $95 \% \mathrm{CI}$ & \\
\hline U.S.-born, No Cross-Border Connection & Ref & Ref & Ref & Ref & Ref & Ref & Ref & Ref & Ref & Ref & Ref & Ref \\
\hline U.S.-born, Any Cross-Border Connection & 0.95 & $(0.86,1.06)$ & & 0.95 & $(0.86,1.06)$ & & 0.97 & $(0.87,1.09)$ & 0.97 & $(0.87,1.09)$ & & \\
\hline Latin American-born, No Cross-Border Connection & 0.95 & $(0.87,1.02)$ & & 0.92 & $(0.85,0.99)$ & * & 0.96 & $(0.85,1.08)$ & 0.93 & $(0.83,1.05)$ & & \\
\hline Latin American-born, Any Cross-Border Connection & 0.98 & $(0.92,1.05)$ & & 0.94 & $(0.88,1.01)$ & & 0.98 & $(0.91,1.06)$ & 0.95 & $(0.87,1.04)$ & & \\
\hline
\end{tabular}

women only $(\operatorname{Exp}(\beta)=0.83,95 \%$ CI: $0.71,0.97)$, and lower five-year follow-up CRP for men only $(\operatorname{Exp}(\beta)=0.75,95 \% \mathrm{CI}$ : 0.58, 0.97) (Appendix Tables A-D). These associations fell to non-significance after further adjustment. In subsequent models, we instead utilized the fourcategory measure of cross-border connection by respondent nativity.

Among women, immigrant respondents who reported any crossborder connection were estimated to have significantly lower levels of IL- 6 and CRP than the reference group of US-born respondents with no cross-border connection in age-adjusted models (Table 2 and Fig. 1).
These significant associations remained after controlling for potential confounders $(\operatorname{Exp}(\beta)=0.81,95 \%$ CI: $0.73,0.90$ for IL-6; $\operatorname{Exp}$ $(\beta)=0.74$, 95\% CI: $0.62,0.89$ for CRP). In models controlling for potential confounders, immigrant women who reported no cross-border ties had lower levels of TNF- $\alpha$ compared to the reference group, although this association was only marginally significant (Exp $(\beta)=0.92$, 95\% CI: $0.85,0.99$ ).

In models for male respondents, immigrants who reported any cross-border connection were estimated to have lower levels of IL-6 $\log$ IL-6

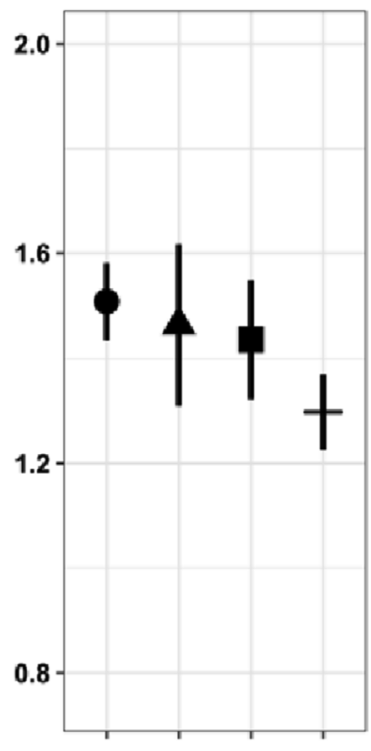

$\log$ CRP

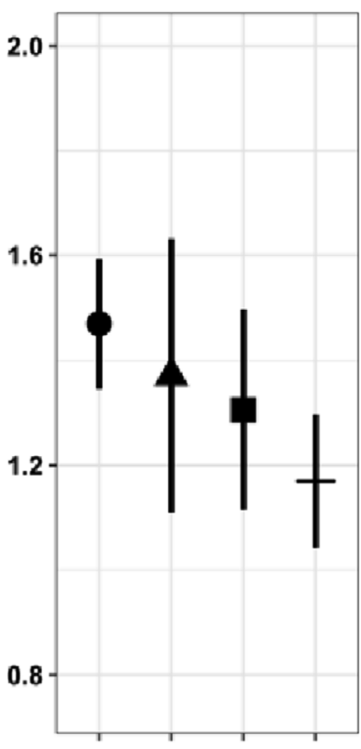

Log TNF-alpha

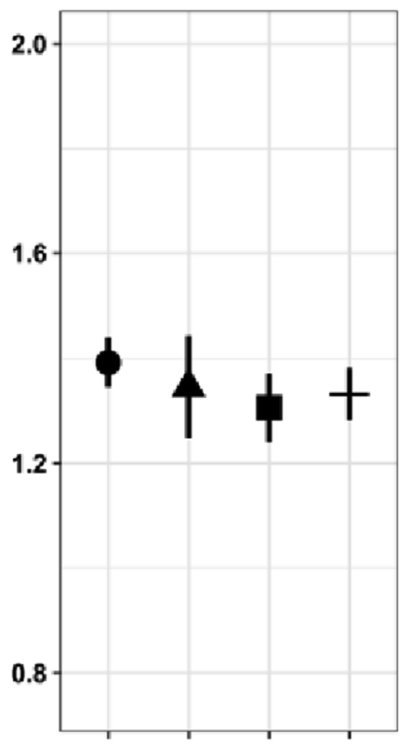

US-bom/Na Crass-Barder Ties

US-born/Gross-Border Ties

LA-born'No Gross-Border Ties † LA-born/Gross-Border Ties

Fig. 1. Predicted values of baseline inflammatory markers by nativity (US versus Latin-American (LA)-born) and baseline cross-border connection, Latina women 60 years and older, Sacramento Area Latino Study on Aging. 
Table 3

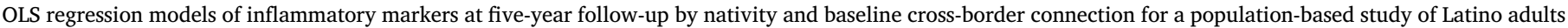
60 years and older.

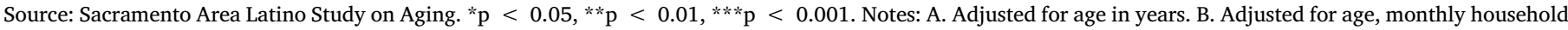
income divided by number of individuals in the household, depression, and local social relationships, all measured at baseline.

\begin{tabular}{|c|c|c|c|c|c|c|c|c|c|c|c|c|}
\hline \multirow[b]{4}{*}{ Nativity/Cross-Border Connection } & \multicolumn{6}{|l|}{ Women } & \multicolumn{6}{|l|}{ Men } \\
\hline & \multicolumn{3}{|l|}{ Model 1a } & \multicolumn{3}{|c|}{ Model 2b } & \multicolumn{3}{|l|}{ Model 1a } & \multicolumn{3}{|c|}{ Model 2b } \\
\hline & \multicolumn{6}{|c|}{$\log$ IL-6 $(n=350)$} & \multicolumn{6}{|c|}{$\log \operatorname{IL}-6(n=248)$} \\
\hline & $\operatorname{Exp}(\beta)$ & $95 \% \mathrm{CI}$ & & $\operatorname{Exp}(\beta)$ & $95 \% \mathrm{CI}$ & & $\operatorname{Exp}(\beta)$ & $95 \% \mathrm{CI}$ & & $\operatorname{Exp}(\beta)$ & $95 \% \mathrm{CI}$ & \\
\hline U.S.-born, No Cross-Border Connection & Ref & Ref & Ref & $\operatorname{Ref}$ & Ref & $\operatorname{Ref}$ & Ref & Ref & $\operatorname{Ref}$ & $\operatorname{Ref}$ & Ref & Ref \\
\hline U.S.-born, Any Cross-Border Connection & 1.14 & $(0.82,1.60)$ & & 1.12 & $(0.81,1.56)$ & & 0.88 & $(0.65,1.18)$ & & 0.88 & $(0.65,1.18)$ & \\
\hline Latin American-born, No Cross-Border Connection & 1.20 & $(0.89,1.61)$ & & 1.17 & $(0.86,1.60)$ & & 0.83 & $(0.59,1.16)$ & & 0.83 & $(0.59,1.16)$ & \\
\hline \multirow[t]{3}{*}{ Latin American-born, Any Cross-Border Connection } & 0.95 & $(0.78,1.16)$ & & 0.92 & $(0.74,1.14)$ & & 0.80 & $(0.62,1.03)$ & & 0.79 & $(0.60,1.06)$ & \\
\hline & \multicolumn{6}{|c|}{$\log$ CRP $(n=550)$} & \multicolumn{6}{|c|}{$\log$ CRP $(n=389)$} \\
\hline & $\operatorname{Exp}(\beta)$ & $95 \% \mathrm{CI}$ & & $\operatorname{Exp}(\beta)$ & $95 \% \mathrm{CI}$ & & $\operatorname{Exp}(\beta)$ & $95 \% \mathrm{CI}$ & & $\operatorname{Exp}(\beta)$ & $95 \% \mathrm{CI}$ & \\
\hline U.S.-born, No Cross-Border Connection & $\operatorname{Ref}$ & Ref & Ref & $\operatorname{Ref}$ & Ref & $\operatorname{Ref}$ & $\operatorname{Ref}$ & $\operatorname{Ref}$ & Ref & $\operatorname{Ref}$ & $\operatorname{Ref}$ & Ref \\
\hline U.S.-born, Any Cross-Border Connection & 1.49 & $(1.03,2.15)$ & * & 1.48 & $(1.03,2.13)$ & * & 0.75 & $(0.52,1.08)$ & & 0.78 & $(0.54,1.13)$ & \\
\hline Latin American-born, No Cross-Border Connection & 1.01 & $(0.74,1.37)$ & & 0.97 & $(0.71,1.34)$ & & 0.97 & $(0.66,1.42)$ & & 0.87 & $(0.59,1.29)$ & \\
\hline \multirow[t]{3}{*}{ Latin American-born, Any Cross-Border Connection } & 0.93 & $(0.74,1.17)$ & & 0.88 & $(0.69,1.13)$ & & 0.74 & $(0.54,1.01)$ & & 0.69 & $(0.49,0.96)$ & * \\
\hline & \multicolumn{6}{|c|}{$\log$ TNF- $\alpha(n=350)$} & \multicolumn{6}{|c|}{ Log TNF- $\alpha(n=248)$} \\
\hline & $\operatorname{Exp}(\beta)$ & $95 \%$ CI & & $\operatorname{Exp}(\beta)$ & $95 \% \mathrm{CI}$ & & $\operatorname{Exp}(\beta)$ & $95 \% \mathrm{CI}$ & & $\operatorname{Exp}(\beta)$ & $95 \% \mathrm{CI}$ & \\
\hline U.S.-born, No Cross-Border Connection & Ref & Ref & Ref & Ref & $\operatorname{Ref}$ & $\operatorname{Ref}$ & $\operatorname{Ref}$ & Ref & Ref & Ref & Ref & Ref \\
\hline U.S.-born, Any Cross-Border Connection & 0.84 & $(0.73,0.96)$ & * & 0.84 & $(0.73,0.96)$ & $*$ & 1.06 & $(0.89,1.27)$ & & 1.07 & $(0.89,1.28)$ & \\
\hline Latin American-born, No Cross-Border Connection & 1.03 & $(0.88,1.21)$ & & 1.02 & $(0.87,1.19)$ & & 1.10 & $(0.90,1.35)$ & & 1.08 & $(0.89,1.31)$ & \\
\hline Latin American-born, Any Cross-Border Connection & 1.01 & $(0.90,1.13)$ & & 0.99 & $(0.89,1.11)$ & & 0.93 & $(0.83,1.05)$ & & 0.92 & $(0.80,1.05)$ & \\
\hline
\end{tabular}
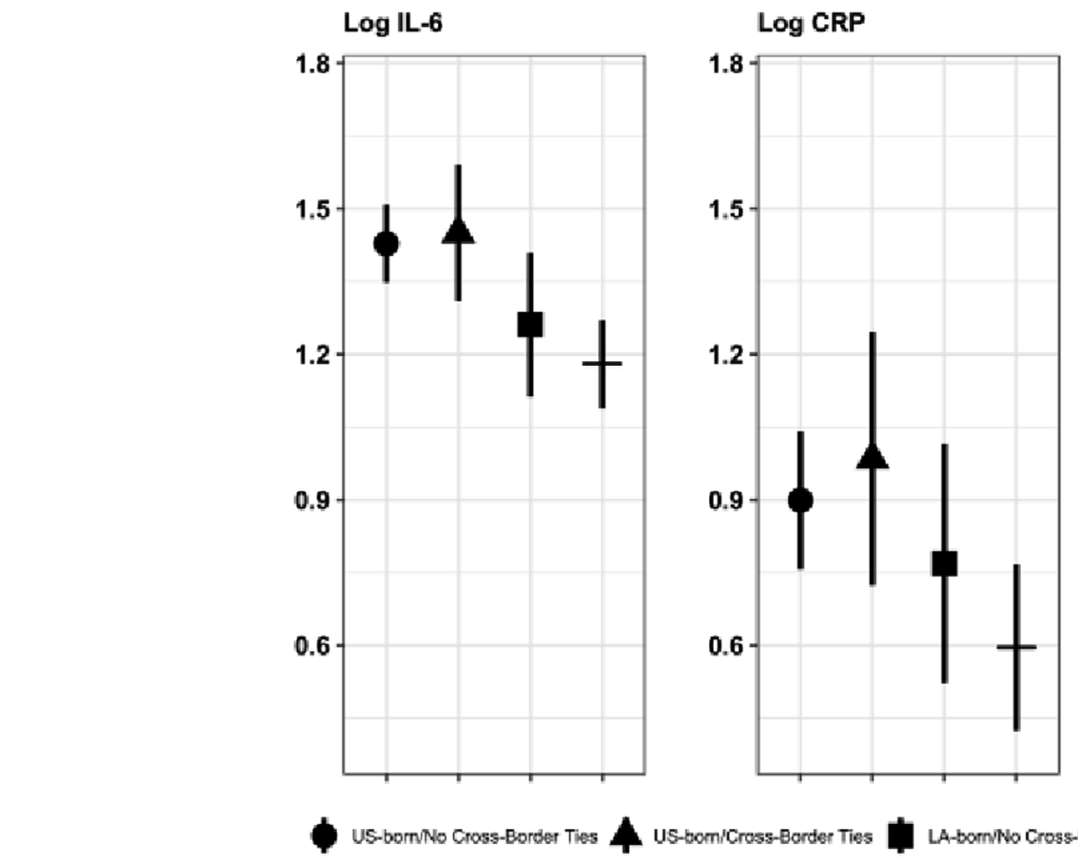

Log TNF-alpha

S-born/Cross-Border Ties

LA-bornilo Cross-Bonder Ties † LA-born/Cross-Border Ties

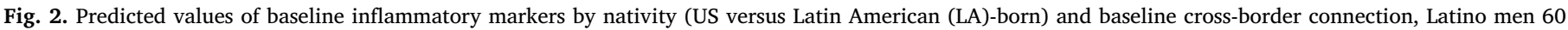
years and older, Sacramento Area Latino Study on Aging.

after adjusting for age only $(\operatorname{Exp}(\beta)=0.82,95 \%$ CI: $073,0.92)$. In models adjusting for potential confounders, immigrant men with crossborder connection had lower levels of both IL- 6 and CRP relative to USborn men with no cross-border connection $(\operatorname{Exp}(\beta)=0.78,95 \% \mathrm{CI}$ : $0.69,0.88$ for IL-6 and $\operatorname{Exp}(\beta)=0.74,95 \%$ CI: $0.57,0.93$ for CRP) (Table 3 and Fig. 2) after adjusting for confounders.

At five-year follow-up, US-born women with any baseline crossborder connection were estimated to have significantly higher CRP relative to the reference group of US-born women with no cross-border contact after adjusting for potential confounders $(\operatorname{Exp}(\beta)=1.48,95 \%$ CI: 1.03, 2.13) (Table 3 and Fig. 3). The same group of US-born women with cross-border ties was estimated to have the lowest levels of TNF- $\alpha$ at five-year follow-up $(\operatorname{Exp}(\beta)=0.84,95 \%$ CI: 0.73, 0.96). Immigrant women with or without cross-border ties had no significant differences in any of the three inflammatory markers at five-year follow-up relative to US-born women with no cross-border contact. Among men, immigrant men with any baseline cross-border connection had significantly lower levels of CRP at five-year follow-up relative to the 

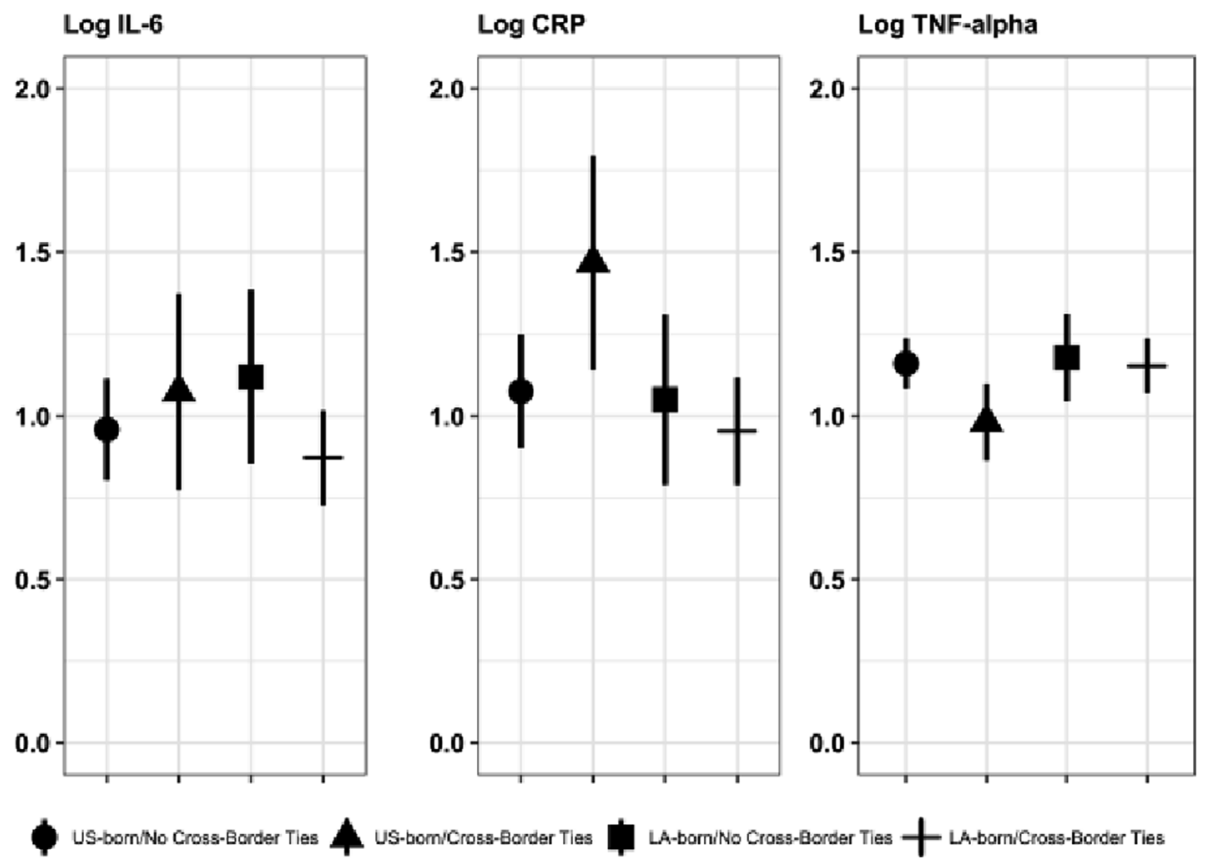

Fig. 3. Predicted values of inflammatory markers at five-year follow-up by nativity (US versus Latin American (LA)-born) and baseline cross-border connection, Latina women 60 years and older, Sacramento Area Latino Study on Aging.
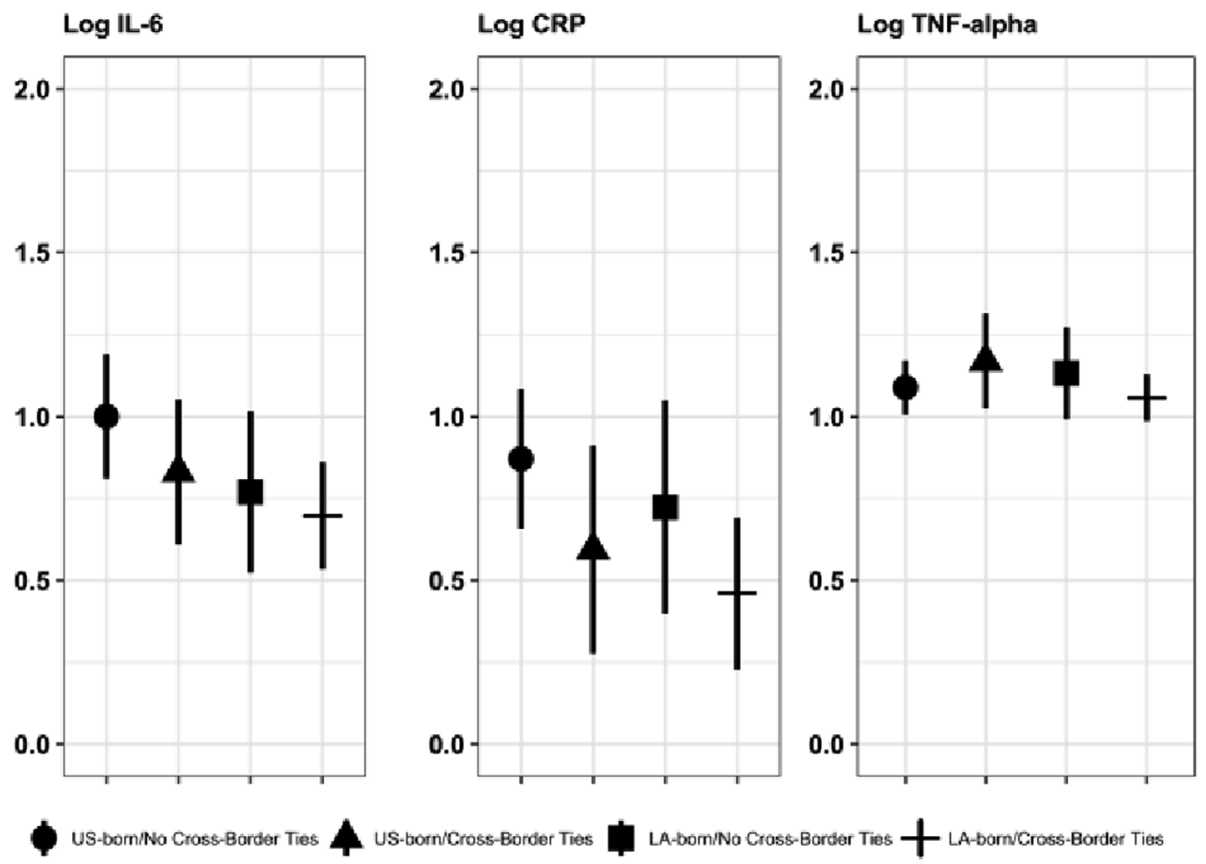

US-born'Gross-Border Ties

LA-bom/Na Grass-Barder Ties † LA-barn/Gross-Border Ties

Fig. 4. Predicted values of inflammatory markers at five-year follow-up by nativity (US versus Latin American (LA)-born) and baseline cross-border connection, Latino men 60 years and older, Sacramento Area Latino Study on Aging.

reference group, even after adjusting for confounders $(\operatorname{Exp}(\beta)=0.69$, 95\% CI: 0.49, 0.96) (Table 3 and Fig. 4).

There were no significant associations between local social relationships and baseline inflammatory markers (not shown). In models of inflammatory markers at five-year follow-up that include both US and Latin American-born respondents, men who reported two local social connections at baseline had lower levels of CRP at five-year follow-up relative to men with no such connections $(\operatorname{Exp}(\beta)=0.51$, $95 \%$ CI: 0.29, 0.90). Similarly, women who reported three or more local social connections at baseline had lower levels of IL-6 at five-year follow-up compared to the reference group without any local social relationships $(\operatorname{Exp}(\beta)=0.70,95 \%$ CI: $0.40,0.98)$.

We also note that reported results are substantially attenuated and null in many cases after controlling for potential mediators of the association between cross-border ties, nativity, and inflammation (Appendix Tables E and F). There was one case in which results were attenuated after excluding cases with inflammatory markers \pm 4 SD about the mean. Results were also sensitive to an alternative specification of the cross-border ties measure, which contrasted respondents who reported "never" or "almost never" communicating with family and friends in Latin America at baseline and those who reported communicating "often" or "always". Further description of these ancillary 
analyses and results tables are presented in the Supplemental Appendix.

\section{Discussion}

Research on the health of immigrants and their descendants has been dominated by a focus on US-based social influences. More recently, scholars have argued for the need to incorporate a transnational perspective into this work, by considering how health outcomes among immigrants and their descendants might vary by connection to places of origin (Abraído-Lanza et al., 2016; Acevedo-Garcia et al., 2012). Crossborder social connections may serve as unique sources of both social support and strain as well as cultural and behavioral influence. These cross-border sociocultural influences may impact mental health or selfreported behavioral outcomes, as has been reported elsewhere (Alcántara et al., 2015a; Torres et al., 2016b). We extended this research to examine whether these cross-border social relationships might also get "under the skin", with links to inflammatory markers that are in turn linked to multiple chronic conditions and mortality.

Overall, we found that cross-border social connection was not significantly associated with inflammation when looking across the entire sample. However, when examining differences by respondent nativity, we found that immigrants who maintained even limited contact with family and friends in Latin America at baseline had lower baseline IL-6 and CRP relative to US-born respondents with no connection to family and friends in Latin America. Consistent with these baseline results, we found that immigrant men with even limited cross-border ties had lower levels of CRP at five-year follow-up compared to their US-born counterparts with no cross-border connection. In contrast, immigrant respondents who reported no cross-border social connection had almost no significant differences in inflammation from their US-born counterparts. While immigrant women with no reported cross-border connection had significantly lower levels of TNF- $\alpha$ at baseline compared to their US-born counterparts who also had no cross-border connection, this association was only marginally significant and should be interpreted with caution. Local social relationships, in contrast, were significantly associated with inflammation at five-year follow-up in two cases: in models of CRP for men, and models of IL- 6 for women.

Findings that cross-border ties were generally linked to lower inflammation among the immigrant sub-sample only are consistent with the expectation that these cross-border relationships are likely stronger and more meaningful for immigrants relative to their US-born counterparts who may have weaker links to extended family networks (Viruell-Fuentes, 2006). However, in models of inflammation at fiveyear follow-up US-born women with any cross-border connection at baseline were found to have both lower TNF- $\alpha$ and higher CRP than their US-born counterparts with no cross-border connection.

Findings of some gender differences, including a persistent beneficial association between cross-border ties and CRP markers for immigrant men only, and of some adverse associations between crossborder connection and inflammation for women, are also consistent with prior research suggesting that immigrant women may experience greater social and emotional strain in transnational family networks. Immigrant women may bear a greater burden than their male counterparts for providing emotional and logistic care for family members both in the U.S. and in places of origin (Viruell-Fuentes, 2006), which may in turn contribute to higher levels of stress as well as stress-related coping behaviors. These stressful components of cross-border ties may temper the degree to which they are associated with lower levels of inflammation among immigrant respondents.

The results are generally suggestive of lower levels of baseline IL- 6 and CRP for immigrant respondents with any degree of cross-border connection, which is consistent with theoretically-informed expectations as well as prior research examining self-reported outcomes and qualitative accounts of cross-border health influences (Acevedo-Garcia et al., 2012; Torres et al., 2016a; Villa-Torres et al., 2017). However, it may be that immigrants who maintain cross-border ties are simply more recently arrived immigrants with stronger connections to family and friends in places of origin and lower levels of inflammation due to other, unmeasured factors (e.g. less cumulative exposure to societal discrimination in the US) (Gallo et al., 2011; Ortiz et al., 2015). Indeed, immigrant respondents in the SALSA study who reported any crossborder ties at baseline had spent an average of 34 years in the US compared with 45 years for their immigrant counterparts with no reported cross-border connection.

Given this concern, we examined the relationship between crossborder ties and inflammatory markers by both nativity and time in the US, where the measure of time in the US contrasts those who spent 35 years or less in the US to those who spent more than 35 years in the US i.e. about the mean number of years spent in the US for the SALSA cohort (Appendix Figures A and B). Immigrants in the US for 35 years or more who maintained any cross-border connection to family and friends in Latin America had the lowest levels of baseline IL-6 (both men and women) and baseline CRP (men only). Immigrant women with fewer than 35 years in the US who maintained cross-border ties had the lowest levels of baseline CRP. Given the small cell sizes for this sixcategory exposure variable (e.g. there are only 46 women and 25 men who have been in the US for $\leq 35$ years and do not report at least some cross-border communication at baseline), these results should be interpreted with caution - and were run for the full baseline sample only. Nevertheless, they suggest that long-stay immigrants may enjoy health benefits resulting from cross-border connection, and that the inflammation advantage for immigrants with cross-border ties may not be explained by differences in time spent in the US.

\subsection{Limitations}

Study findings should be viewed in light of a number of limitations. For one, the sample is limited to primarily Latin American-origin older adults born in Latin America and the US and residing in a specific region of Northern California; the results may not be generalizable to other immigrant or second-generation populations. In addition, respondents were on average 70 years old at baseline. The meaning of local and cross-border social relationships might be distinct for older adults as compared to individuals in mid or early-life; local connections might be of greater importance to older adults who may need hands-on care with activities of daily living or with managing medical conditions. Declines in physical and cognitive functioning may also make it challenging for older adults to maintain cross-border relationships through visits home or even through frequent phone calls, which could weaken these long-distance connections.

We also note that the measure of respondents' cross-border ties does not address the quality of respondents' connections to family and friends living in Latin America, including indicators of social support and strain, which may be important predictors of inflammatory burden (Yang et al., 2014). The measures also do not indicate the types of relationships maintained (e.g. children, extended family members) or specify the frequency of cross-border connection. To our knowledge, data sources that include such nuanced measures of cross-border ties alongside biological indicators of health do not exist. However, we emphasize that our findings were sensitive to the specification of the measure of cross-border connection, underscoring the critical importance of understanding detailed variation in the forms and frequency of cross-border connection in relationship to health outcomes in future research.

Additional limitations include the relatively small sample size, particularly for follow-up analyses, which could limit power to detect some associations and could be driving some unexpected results. The lack of repeated measures of social ties also means that we were unable to account for the potentially reciprocal association between social relationships and inflammation (Eisenberger et al., 2017). While we do examine associations with inflammatory markers at five-year follow-up, repeated measures of cross-border ties would be necessary to model 
reciprocal associations. A related point is that given that we lack an updated measure of cross-border connection, it is unclear whether or not cross-border social connections measured at baseline persisted to five-year follow-up. We may be missing underlying differences in respondents who continued to have cross-border connections at five-year follow-up and those who no longer maintained these connections. We therefore encourage replication of our findings as well as extensions that include more nuanced and repeated measures of cross-border ties.

Our findings nevertheless contribute to a nascent body of research that suggests that cross-border connection may serve as an important social determinant of health for immigrants and their descendants in the US. This study moves this body of literature forward by examining the association between cross-border ties and biomarkers of inflammation. Our findings lend qualified support to the idea that crossborder ties might be considered as an important components of immigrants' social networks and a potential source of heterogeneity in the immigrant health advantage. Moreover, the results might serve as a catalyst for future data collection and analysis efforts that seek to shed light on the social determinants of immigrant health using a transnational approach, as well as efforts to identify the mechanisms by which cross-border connection might impact the health of immigrants and their family members.

\section{Acknowledgements}

Research reported in this publication was supported by the National Institutes of Health, including the National Institute on Aging under Award Numbers K01AG056602 to Jacqueline M. Torres and R01AG12975 to Mary N. Haan and the National Institute of Diabetes and Digestive and Kidney Diseases under Award Numbers R01 DK60753 to Mary N. Haan and R01DK087864 to Allison Aiello. Allison Aiello is also supported by the National Institutes of Health under Award Numbers P2CHD050924, P60MD002249. The content is solely the responsibility of the authors and does not necessarily represent the official views of the National Institutes of Health.

\section{Appendix A. Supplementary data}

Supplementary data related to this article can be found at http://dx. doi.org/10.1016/j.socscimed.2018.05.028.

\section{References}

Abraído-Lanza, A.F., Echeverría, S.E., Flórez, K.R., 2016. Latino immigrants, acculturation, and health: promising new directions in research. Annu. Rev. Publ. Health 37, 219-236.

Abrego, L., 2014. Sacrificing Families: Navigating Laws, Labor, and Love across Borders. Stanford University Press, Stanford, CA.

Acevedo-Garcia, D., Sanchez-Vaznaugh, E.V., Viruell-Fuentes, E.A., Almeida, J., 2012. Integrating social epidemiology into immigrant health research: a cross-national framework. Soc. Sci. Med. 75 (12), 2060-2068.

Aiello, A.E., Haan, M.N., Pierce, C.M., Simanek, A.M., Liang, J., 2008. Persistent infection, inflammation, and functional impairment in older Latinos. J. Gerontol. A Biol. Sci. Med. Sci. 63 (6), 610-618.

Alcántara, C., Chen, C.N., Alegría, M., 2015a. Transnational ties and past-year major depressive episodes among Latino immigrants. Cult. Divers Ethnic Minor. Psychol. 21 (3), 486-495

Alcántara, C., Molina, K.M., Kawachi, I., 2015b. Transnational, social, and neighborhood ties and smoking among Latino immigrants: does gender matter? Am. J. Publ. Health 105 (4), 741-749.

Arenas, E., Goldman, N., Pebley, A.R., Teruel, G., 2015. Return migration to Mexico: does health matter? Demography 52 (6), 1853-1868.

Bajaj, A., John-Henderson, N.A., Cundiff, J.M., Marsland, A.L., Manuck, S.B., Kamarck, T.W., 2016. Daily social interactions, close relationships, and systemic inflammation in two samples: healthy middle-aged and older adults. Brain Behav. Immun. 58, 152-164.

Berkman, L.F., Glass, T., Brissette, I., Seeman, T.E., 2000. From social integration to health: Durkheim in the new millennium. Soc Sci. Med. 51 (6), 843-857.

Cole, S.R., Hernán, M.A., 2008. Constructing inverse probability weights for marginal structural models. Am. J. Epidemiol. 168 (6).

Crimmins, E., Kim, J., Alley, D., Karlamangla, A., Seeman, T., 2007. Hispanic paradox in biological risk profiles. Am. J. Publ. Health 97 (7), 1305-1310.
Das, A., 2016. Psychosocial distress and inflammation: which way does causality flow? Soc. Sci. Med. 170, 1-8.

Daviglus, M.L., Talavera, G.A., Avilés-Santa, L., Allison, M., Cai, J., Criqui, M.H., et al., 2012. Prevalence of major cardiovascular risk factors and cardiovascular diseases among Hispanic/Latino individuals of diverse backgrounds in the United States. J. Am. Med. Assoc. 308 (17), 1775-1784.

Eisenberger, N.I., Cole, S.W., 2012. Social neuroscience and health: neurophysiological mechanisms linking social ties with physical health. Nat. Neurosci. 15 (5), 669-674.

Eisenberger, N.I., Moieni, M., Inagaki, T.K., Muscatell, K.A., Irwin, M.R., 2017. In sickness and in health: the co-regulation of inflammation and social behavior. Neuropsychopharmacology 42 (1), 242-253.

Ford, E.S., Loucks, E.B., Berkman, L.F., 2006. Social integration and concentrations of C reactive protein among US adults. Ann. Epidemiol. 16 (2), 78-84.

Gallo, L.C., Jiménez, J.A., Shivpuri, S., Espinosa de los Monteros, K., Mills, P.J., 2011. Domains of chronic stress, lifestyle factors, and allostatic load in middle-aged Mexican-American women. Ann. Behav. Med. 41 (1), 21-31.

Glei, D.A., Goldman, N., Ryff, C.D., Lin, Y.-H., Weinstein, M., 2012. Social relationships and inflammatory markers: an analysis of Taiwan and the U.S. Soc. Sci. Med. 74 (12), 1891-1899.

Haan, M.N., Mungas, D.M., Gonzalez, H.M., Ortiz, T.A., Acharya, A., Jagust, W.J., 2003. Prevalence of dementia in older Latinos: the influence of Type 2 diabetes mellitus, stroke, and genetic factors. J. Am. Geriatr. Soc. 51 (2), 169-177.

Jasso, G., Massey, D.S., Rosenzweig, M.R., Smith, J.P., 2004. Immigrant health: selectivity and acculturation. In: Anderson, N.B., Bulatao, R.A., Cohen, B. (Eds.), Critical Perspectives on Racial and Ethnic Differences in Health in Late Life. The National Academies Press, Washington, D.C.

Kaptoge, S., Di Angelantonio, E., Lowe, G., Pepys, M.B., Thompson, S.G., Collins, R., Danesh, J., ... Emerging Risk Factors Collaboration, 2010. C-reactive protein concentration and risk of coronary heart disease, stroke, and mortality: an individual participant meta-analysis. Lancet 375 (9709), 132-140.

Kiecolt-Glaser, J.K., Preacher, K.J., MacCallum, R.C., Atkinson, C., Malarkey, W.B., Glaser, R., 2003. Chronic stress and age-related increases in the proinflammatory cytokine IL-6. Proc. Natl. Acad. Sci. U. S. A. 100 (15), 9090-9095.

Kiecolt-Glaser, J.K., Gouin, J.P., Hantsoo, L., 2010. Close relationships, inflammation, and health. Neurosci. Biobehav. Rev. 35 (1), 33-38.

Ledue, T.B., Weiner, D.L., Sipe, J.D., Poulin, S.E., Collins, M.F., Rifai, N., 1998. Analytical evaluation of particle-enhanced immunonephelometric assays for C-reactive protein, serum amyloid A and mannose-binding protein in human serum. Ann. Clin. Biochem. 35 (Pt 6), 745-753.

Loucks, E.B., Berkman, L.F., Gruenewald, T.L., Seeman, T.E., 2006. Relation of social integration to inflammatory marker concentrations in men and women 70 to 79 years. Am. J. Cardiol. 97 (7), 1010-1016.

Medina-Inojosa, J., Jean, N., Cortes-Bergoderi, M., Lopez-Jimenez, F., 2014. The Hispanic paradox in cardiovascular disease and total mortality. Prog. Cardiovasc. Dis. 57 (3), 286-292.

Menjívar, C., 2002. The ties that heal: Guatemalan immigrant women's networks and medical treatment. Int. Migrat. Rev. 36 (2), 437-466.

Menjívar, C., 2012. Transnational parenting and immigration law: Central Americans in the United States. J. Ethnic Migrat. Stud. 38 (2), 301-322.

Ortiz, M.S., Myers, H.F., Schetter, C.D., Rodriguez, C.J., Seeman, T.E., 2015. Psychosocial predictors of metabolic syndrome among Latino groups in the Multi-Ethnic Study of Atherosclerosis (MESA). PLoS One 10 (4), e0124517.

Peek, M.K., Cutchin, M.P., Salinas, J.J., Sheffield, K.M., Eschbach, K., Stowe, R.P., Goodwin, J.S., 2010. Allostatic load among non-Hispanic Whites, non-Hispanic Blacks, and people of Mexican origin: effects of ethnicity, nativity, and acculturation. Am. J. Publ. Health 100 (5), 940-946.

Radloff, L.C., 1977. The CES-D scale, a self-report depression scale for research in the general population. Appl. Psychol. Meas. 1 (3), 385-401.

R\&D Systems Inc, 2017a. QuantiGlo ${ }^{\circ}$ ELISA human IL-6 immunoassay. In: Vol. Catalog Number Q6000B. R\&D Systems, Inc, Minneapolis, MN Retrieved from: https:// resources.rndsystems.com/pdfs/datasheets/q6000b.pdf.

R\&D Systems Inc, 2017b. QuantiGlo ELISA Human TNF- $\alpha$ Immunoassay. R\&D Systems, Inc, Minneapolis, MN Retrieved from: https://resources.rndsystems.com/pdfs/ datasheets/qta00b.pdf.

Ridker, P.M., Hennekens, C.H., Buring, J.E., Rifai, N., 2000a. C-Reactive protein and other markers of inflammation in the prediction of cardiovascular disease in women. N. Engl. J. Med. 342, 836-843.

Ridker, P.M., Rifai, N., Stampfer, M.J., Hennekens, C.H., 2000b. Plasma concentration of interleukin- 6 and the risk of future myocardial infarction among apparently healthy men. Circulation 101 (15), 1767-1772.

Roberts, E.T., Haan, M.N., Dowd, J.B., Aiello, A.E., 2010. Cytomegalovirus antibody levels, inflammation, and mortality among elderly Latinos over 9 years of follow-up. Am. J. Epidemiol. 172 (4), 363-371. http://dx.doi.org/10.1093/aje/kwq177.

Torres, J.M., 2013. Cross-border ties and self-rated health status for young Latino adults in Southern California. Soc. Sci. Med. 81, 79-86.

Torres, J.M., Alcántara, C., Rudolph, K.E., Viruell-Fuentes, E.A., 2016a. Cross-border ties as sources of risk and resilience: do cross-border ties moderate the relationship between migration-related stress and psychological distress for Latino migrants in the United States? J. Health Soc. Behav. 57 (4), 436-452.

Torres, J.M., Lee, A., González, H.M., Garcia, L., Haan, M.N., 2016b. A longitudinal analysis of cross-border ties and depression for Latino adults. Soc. Sci. Med. 160, 111-119.

Villa-Torres, L., González-Vázquez, T., Fleming, P.J., González-González, E.L., InfanteXibille, C., Chavez, R., Barrington, C., 2017. Transnationalism and health: a systematic literature review on the use of transnationalism in the study of the health practices and behaviors of migrants. Soc. Sci. Med. 183, 70-79. 
Viruell-Fuentes, E.A., 2006. "My heart is always there": the transnational practices of first-generation Mexican immigrant and second-generation Mexican American women. Identities-Global Studies in Culture and Power 13 (3), 335-362.

Viruell-Fuentes, E.A., Schulz, A.J., 2009. Toward a dynamic conceptualization of social ties and context: implications for understanding immigrant and Latino health. Am. J. Publ. Health 99 (12), 2167-2175.

Waldinger, R., 2015. The Cross-border Connection: Immigrants, Emigrants, and Their Homelands. Harvard University Press, Cambridge, MA.

Yaffe, K., Haan, M., Blackwell, T., Cherkasova, E., Whitmer, R.A., West, N., 2007.
Metabolic syndrome and cognitive decline in elderly Latinos: findings from the Sacramento area Latino study of aging study. J. Am. Geriatr. Soc. 55 (5), 758-762. Yang, Y.C., Schorpp, K., Harris, K.M., 2014. Social support, social strain and inflammation: evidence from a national longitudinal study of U.S. adults. Soc. Sci. Med. 107, $124-135$.

Yang, Y.C., Boen, C., Gerken, K., Li, T., Schorpp, K., Harris, K.M., 2016. Social relationships and physiological determinants of longevity across the human life span. Proc. Natl. Acad. Sci. U. S. A. 113 (3), 578-583. 